\title{
ENCAPSULAÇÃO DOS COMPOSTOS BIOATIVOS DO Butia quaraimana A PARTIR DA TÉCNICA DE LIOFILIZAÇÃO
}

\author{
G. F. WESTPHALEN ${ }^{1}$, V. O. de FREITAS ${ }^{1}$, V. ROSSETO ${ }^{1}$ E G. S. ROSA ${ }^{1}$ \\ ${ }^{1}$ Universidade Federal do Pampa, Curso de Engenharia Química \\ E-mail para contato: vit_freitas@hotmail.com
}

\begin{abstract}
RESUMO - O objetivo do presente estudo foi caracterizar o suco de butiá in natura e realizar a encapsulação dos compostos bioativos através da técnica de liofilização. Foram realizadas análises do suco para teor de umidade e concentrações de sólidos totais a partir do método da estufa a $105{ }^{\circ} \mathrm{C}$ por $24 \mathrm{~h}$, massa específica através da picnometria líquida, determinação de antocianinas pelo método de Fuleki e Francis, carotenoides segundo o método descrito por Rodriguez-Amaya e quantificação de fenóis pela metodologia de Singleton e Rossi. Como material encapsulante foi utilizada a goma arábica em diferentes proporções (1:2 e 1:4 - suco:goma). Para avaliar a estabilidade dos compostos encapsulados foi realizada análise termogravimétrica (TGA). Os termogramas das amostras indicaram que a goma arábica possui maior estabilidade térmica do que o suco puro liofilizado, apresentando maior perda de massa em temperaturas próximas a $300^{\circ} \mathrm{C}$, enquanto o suco liofilizado apresentou picos em 50, 200 e 300 ${ }^{\circ} \mathrm{C}$. Já os picos para o suco encapsulado com a goma arábica apresentaram maior perda de massa em temperatura próximas a $325^{\circ} \mathrm{C}$, sugerindo que os compostos presentes no suco do butiá foram protegidos pelo material de parede.
\end{abstract}

\section{INTRODUÇÃO}

As palmeiras estão dentre as plantas mais antigas do globo terrestre, havendo registros de sua existência há mais de 120 milhões de anos (Lorenzi et al., 2004). No Rio Grande do Sul ocorrem seis gêneros de palmeiras nativas, com destaque para o gênero butiá (Rossato, 2007). O interesse por frutos de espécies nativas tem aumentado por se acreditar que o consumo dos mesmos melhora a saúde humana. Os benefícios à saúde têm sido associados principalmente aos compostos bioativos (carotenoides, compostos fenólicos e vitamina C) com propriedades antioxidantes (Fonseca, 2012).

As antocianinas e os carotenoides são pigmentos naturais pertencentes ao grupo dos compostos bioativos que apresentam capacidade antioxidante. São bastante visados pela indústria alimentícia para a substituição dos corantes artificiais (Teixeira et al., 2008).

A encapsulação compreende um conjunto de diversas técnicas que permitem o desenvolvimento de formulações, em que o seu conteúdo é protegido e a sua liberação pode ser modificada com o objetivo de atuar em um determinado local, por um determinado período de tempo e uma velocidade específica (Brasileiro et al., 2006). As cápsulas podem ser obtidas por diferentes técnicas, onde destaca-se a liofilização, técnica que utiliza baixas temperaturas, proporcionando a preservação do núcleo. Esta é baseada na desidratação do 
produto primeiramente congelado, e logo submetido ao processo de sublimação à vácuo (Azeredo, 2005). A goma arábica é muito utilizada em processos de encapsulação de compostos lipossolúveis, pigmentos do grupo carotenoides e flavors devido à formação de uma emulsão estável e retenção dos compostos voláteis. Este composto destaca-se por possuir sabor insípido, não influenciando no sabor do produto final (Rutz, 2013).

O presente estudo teve como finalidade caracterizar o suco do fruto do Butia quaraimana, quanto as suas propriedades físico-químicas, além de encapsular o mesmo utilizando a técnica de liofilização e como material de parede a goma arábica em diferentes proporções.

\section{MATERIAIS E MÉTODOS}

\subsection{Obtenção do fruto e do suco do butiá}

No presente trabalho utilizou-se como matéria prima frutos da espécie Butia quaraimana Deble \& Marchiori, com coloração da casca (epicarpo) vermelha. Tal espécie ocorre no Bioma Pampa, sendo endêmica do Palmar de Coatepe, no município de Quaraí, RS (Deble et al., 2012). Os frutos foram colhidos manualmente, lavados, sanitizados e congelados.

Para a obtenção do suco primeiramente triturou-se a polpa, adicionando-se água na proporção de 40 g polpa: 100mL de água.

\subsection{Caracterização físico química do suco}

A concentração dos sólidos presentes no suco foi realizada a partir do método da estufa na temperatura de $105^{\circ} \mathrm{C}$ durante $24 \mathrm{~h}$, em triplicata. A concentração de sólidos solúveis foi obtida utilizando um refratômetro portátil.

O conteúdo de antocianinas foi determinado a partir da metodologia de Fuleki e Francis (1968), adicionando-se ao suco, etanol como solvente extrator. Esta mistura foi homogeneizada e filtrada. Após foi realizada a leitura em espectrofotômetro, utilizando $\Lambda=$ $535 \mathrm{~nm}$.

O teor de carotenoides totais foi obtido a partir da metodologia de Rodriguez-Amaya (1999), adicionando-se ao suco, acetona gelada como solvente extrator. Logo realizou-se a filtração e o extrato concentrado foi transferido para um funil de separação e adicionou-se éter de petróleo e água. Após a separação das fases, foi realizada a leitura em espectrofotômetro, utilizando-se $\Lambda=450 \mathrm{~nm}$.

A determinação dos compostos fenólicos foi realizada de acordo com o método descrito por Singleton e Rossi (1965), com algumas adaptações. Para a extração, adicionou-se metanol ao suco e logo filtrou-se esta mistura. Retirou-se uma alíquota do extrato obtido da filtração e adicionou-se água destilada, Folin-Ciocalteu e carbonato de sódio 7,5\% deixando-se em repouso no escuro por $2 \mathrm{~h}$. Assim, foi realizada a leitura em espectrofotômetro utilizando-se $\Lambda$ $=760 \mathrm{~nm}$. 


\subsection{Obtenção e caracterização das cápsulas}

Foram utilizadas as proporções 1:2 e 1:4 (suco: goma arábica). Ambas as proporções foram realizadas considerando a massa de sólidos seco presente no suco e na goma.

Para a completa homogeneização do suco com a goma arábica a etapa de mistura destes componentes foi padronizada realizando para todos os experimentos agitação mecânica em 280 rpm por $10 \mathrm{~min}$. As amostras foram congeladas por $24 \mathrm{~h}$ na temperatura de $-20{ }^{\circ} \mathrm{C}$ e após liofilizadas por $48 \mathrm{~h}$ a uma temperatura de $-18{ }^{\circ} \mathrm{C}$. Para possibilitar uma análise comparativa também foi liofilizada uma amostra pura do suco do butiá, nas mesmas condições do suco com a goma.

Para a verificação da estabilidade térmica dos compostos presentes no suco puro liofilizado e nas amostras encapsuladas, realizou-se a análise termogravimétrica (TGA), utilizando o equipamento Shimadzu TGA 50. A análise consistiu em pesar aproximadamente $3 \mathrm{mg}$ de amostra que foram submetidas ao aquecimento a uma taxa de $10{ }^{\circ} \mathrm{C} / \mathrm{min}$ entre $25-$ $400{ }^{\circ} \mathrm{C}$ com um fluxo de nitrogênio de $20 \mathrm{~mL} / \mathrm{min}$.

\section{RESULTADOS E DISCUSSÃO}

A Tabela 1 apresenta os resultados para as análises físico-químicas do suco do butiá, fazendo uma comparação com a literatura apresentada por Fonseca (2012) para a espécie Butia odorata.

Tabela 1 - Caracterização físico-química do suco do butiá.

\begin{tabular}{ccc}
\hline Caracterização & Resultados & Literatura \\
\hline Concentração de sólidos totais $(\%)$ & $0,11-0,29$ & - \\
Concentração de sólidos solúveis $\left({ }^{\text {o Brix }}\right)$ & $2-5$ & $10,6-14,8$ \\
$\mathrm{pH}$ & $3,9-4,1$ & $2,8-3,17$ \\
Antocianinas $\left(\mathrm{mg} \cdot 100 \mathrm{~g}^{-1}\right)$ & $1,1-12$ & $1,95-14,23$ \\
Carotenoides $\left(\mu \mathrm{g} . \mathrm{g}^{-1}\right)$ & $13,1-17,01$ & $82,9-223,1$ \\
Massa específica $\left(\mathrm{kg} / \mathrm{m}^{3}\right)$ & $909,8-920,0$ & - \\
\hline
\end{tabular}

Os resultados obtidos para a caracterização dos frutos diferem da literatura, com exceção para o teor de antocianinas contidas no fruto, o que pode ser explicado ao fato do suco ter sido obtido a partir de diferentes espécies de butiá além da diferente preparação da amostra analisada. Enquanto no presente estudo as análises foram feitas do suco, no trabalho de Fonseca (2012) as análises foram realizadas em geleias preparadas a partir do suco do butiá, o qual apresenta maior concentração do fruto.

A Figura 1 ilustra o aspecto visual do suco puro e com goma arábica antes e após o processo de liofilização. 
Figura 1 - Extrato puro e com goma arábica antes e após a liofilização.

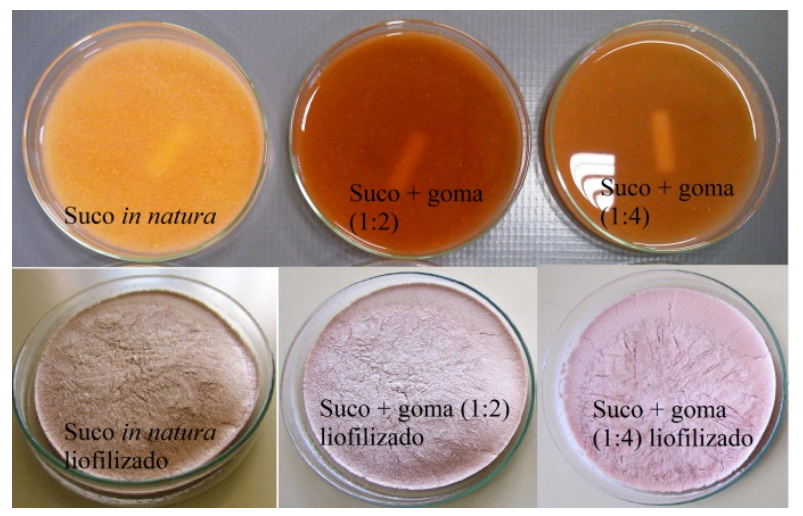

As Figuras 2, 3, 4 e 5 apresentam as análises termogravimétricas obtidas para a goma arábica, para o suco liofilizado e para o suco do butiá encapsulado com 1:2 e 1:4 de goma arábica, respectivamente.

Figura 2 - TGA para goma arábica.

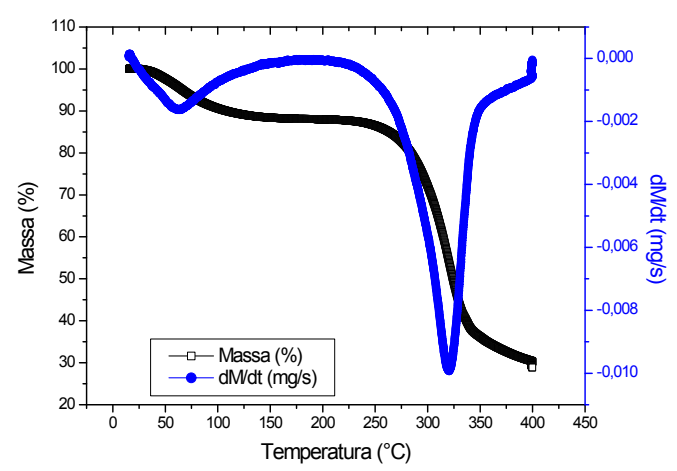

Figura 3 - TGA para o suco de butiá liofilizado

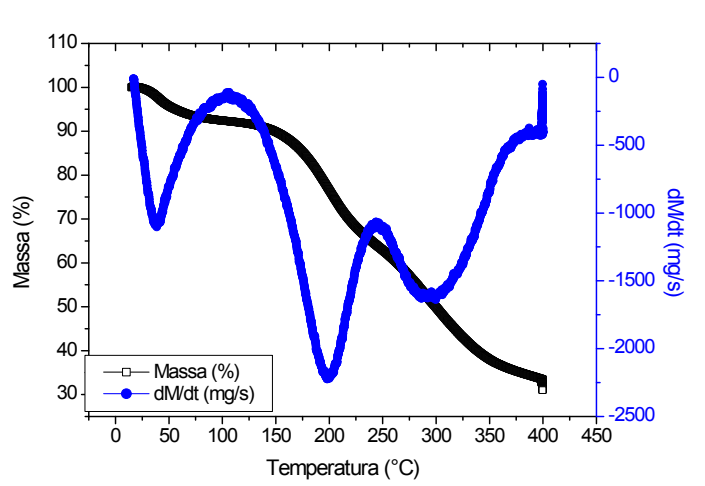

Figura 4 - TGA para o suco de butiá encapsulado 1:2.

Figura 5 - TGA para o suco de butiá encapsulado 1:4. 

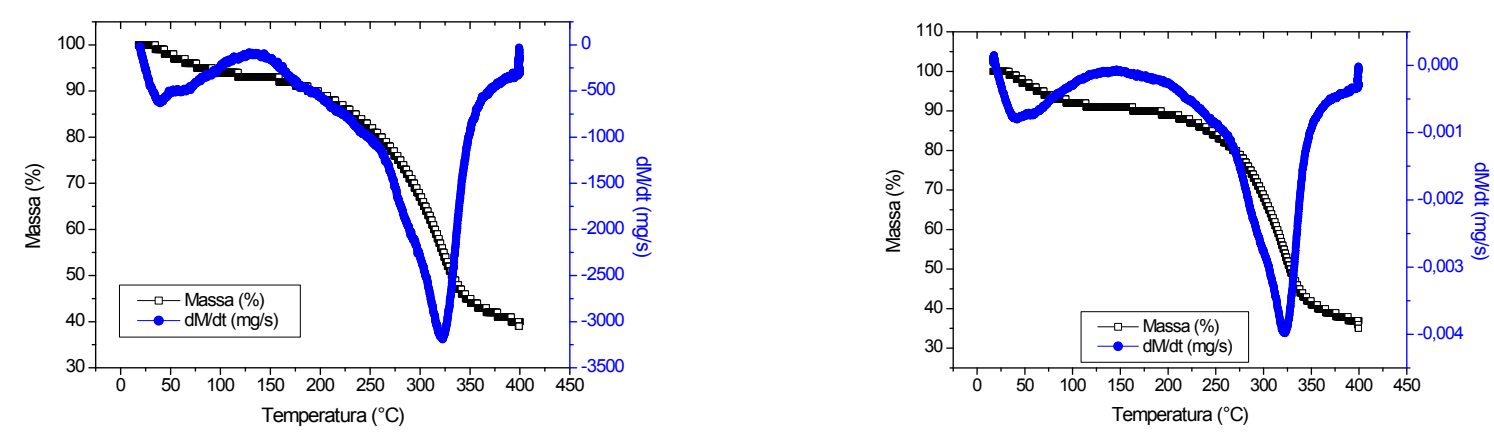

A partir da análise das Figuras 2, 3, 4 e 5 observa-se que a goma arábica apresentou maior estabilidade térmica do que o suco puro liofilizado, apresentando maior perda de massa em temperaturas próximas a $300{ }^{\circ} \mathrm{C}$, enquanto o suco puro liofilizado apresentou picos em 50 , 200 e $300^{\circ} \mathrm{C}$, o que indica a sensibilidade térmica dos compostos que compõem o suco. As amostras quando analisados por TGA, sob atmosfera de nitrogênio, apresentam uma primeira perda de massa correspondente a evaporação da água presente, e uma segunda referente a degradação que ocorre em temperaturas normalmente acima de $200{ }^{\circ} \mathrm{C}$ (Trotta et al., 2000), comportamento apresentado pela goma arábica e pelas amostras encapsuladas.

A maneira mais comum de se detectar a encapsulação utilizando o TGA, consiste em comparar a temperatura do início da degradação da molécula a ser encapsulada com a cápsula. Para confirmar a encapsulação as cápsulas devem apresentar maior resistência térmica quando comparada com o composto individualizado (Ammar et al., 2006; ARAÚJO et al., 2007). Desta forma sugere-se que os compostos presentes no suco do butiá foram protegidos pelo material de parede, pois os picos para o suco encapsulado com a goma arábica apresentaram maior resistência térmica do que o suco puro liofilizado, apresentando maiores perdas de massa em temperatura próximas a $325^{\circ} \mathrm{C}$.

\section{REFERÊNCIAS BIBLIOGRÁFICAS}

AMMAR, H. O. SALAMA, H. A. GHORAB, M. MAHMOUD, A. A. Formulation and biological evaluation of glimepiride-cyclodextrin-polymer systems. International Journal of Pharmaceutics, v. 309, p. 129-138, 2006.

ARAÚJO, M. V. G., VIEIRA, E. K. B., LÁZARO, G. S., COGENERO, L. S., FERREIRA, O. P., ALMEIDA, L. E. Inclusion complexes of pyrimethamine in 2- hydroxypropyl-bcyclodextrin: Characterization, phase solubility and molecular modeling. Bioorganic and Medicinal Chemistry, v. 15, p. 5752-5759, 2007.

AZEREDO, H. M. C. Microencapsulação: aplicação à tecnologia de alimentos. Alimento $e$ Nutrição, p 89 - 95, 2005.

BRASILEIRO, J. S. L Microencapsulação de Compostos Bioactivos: inovação em diferentes áreas. (Mestrado em Ciências Farmacêuticas) Universidade Fernando Pessoa, 2011. 
DEBlE, L. P.; MARCHIORI, J. N. C.; ALVES, F. S.; OLIVEIRA-DEBLE, A. S. Butia quaraimana (Arecaceae), uma nova espécie para o Rio Grande do Sul (Brasil). Balduinia, v.33, p.9-20, 2012.

FONSECA, L.X. Caracterização de frutos de butiazeiro (Butia odorata Barb. Rodr.) Noblick \& Lorenzi e estabilidade de seus compostos bioativos na elaboração e armazenamento de geleias. (Mestrado em Ciência e Tecnologia Agroindustrial) Universidade Federal de Pelotas, 2012.

LORENZI, H.; SOUZA, H.M.; COSTA, J.T.; CERQUEIRA, L.S.C.; FERREIRA, E. Palmeiras brasileiras e exóticas cultivadas. Nova Odessa: Instituto Plantarum de Estudos da Flora, p. 375, 2004.

ROSSATO, M. Recursos genéticos de palmeiras nativas do gênero Butia do Rio Grande do Sul. (Doutorado em Agronomia) Universidade Federal de Pelotas, Pelotas, 2007.

RUTZ, J. K Caracterização e Microencapsulação de Suco de Pitanga Roxa (Eugenia uniflora L.). (Mestrado em Ciências e Tecnologia de Alimentos) Universidade Federal de Pelotas, 2013.

TEIXEIRA, L. N.; STRINGHETA, P. C.; OLIVEIRA, F. A. de. Comparação de métodos para quantificação de antocianinas. Revista Ceres, v. 55, p. 297-304, 2008.

TROTTA, F., ZANETTI, M., CAMINO, G. Thermal degradation of cyclodextrins. Polymer Degradation and Stability, v. 69, p. 373-379, 2000. 